\title{
ASO Visual Abstract: Laparoscopic Versus Robot-Assisted Versus Transanal Low Anterior Resection: 3-Year Oncologic Results of a Population-Based Cohort in Experienced Centers
}

T. A. Burghgraef, MD ${ }^{1,2}$ (1) J. C. Hol, $\mathrm{MD}^{3,4}$, M. L. Rutgers, $\mathrm{MD}^{5}$, R. M. P. H. Crolla, $\mathrm{MD}^{6}$, A. A. W. van Geloven, $\mathrm{MD}, \mathrm{PhD}^{7}$, R. Hompes, $\mathrm{MD}, \mathrm{PhD}^{5}$, J. W. A. Leijtens, $\mathrm{MD}, \mathrm{PhD}^{8}$, A. Pronk, MD, $\mathrm{PhD}^{9}$, A. B. Smits, MD, $\mathrm{PhD}^{10}$, J. B. Tuynman, MD, $\mathrm{PhD}^{4}$, E. G. G. Verdaasdonk, $\mathrm{MD}, \mathrm{PhD}^{11}$, F. Polat, MD, $\mathrm{PhD}^{12}$, P. M. Verheijen, MD, PhD ${ }^{1}$, C. Sietses, MD, $\mathrm{PhD}^{3}$, and E. C. J. Consten, MD, PhD ${ }^{1,2}$

${ }^{1}$ Department of Surgery, Meander Medical Center, Amersfoort, the Netherlands; ${ }^{2}$ Department of Surgery, University Medical Center Groningen, Groningen, the Netherlands; ${ }^{3}$ Department of Surgery, Hospital Gelderse Vallei, Ede, the Netherlands; ${ }^{4}$ Department of Surgery, Amsterdam UMC, Amsterdam, the Netherlands; ${ }^{5}$ Department of Surgery, Amsterdam UMC, Locatie AMC, Amsterdam, the Netherlands; ${ }^{6}$ Department of Surgery, Amphia Hospital, Breda, the Netherlands; ${ }^{7}$ Department of Surgery, Tergooi Hospital, Hilversum, the Netherlands; ${ }^{8}$ Department of Surgery, Laurentius Hospital, Roermond, the Netherlands; ${ }^{9}$ Department of Surgery, Diakonessenhuis, Utrecht, the Netherlands; ${ }^{10}$ Department of Surgery, St. Antonius Hospital, Nieuwegein, the Netherlands; ${ }^{11}$ Department of Surgery, Jeroen Bosch Hospital, Den Bosch, the Netherlands; ${ }^{12}$ Department of Surgery, Canisius Wilhelmina Hospital, Nijmegen, the Netherlands

Results regarding oncologic outcomes after laparoscopic, robot-assisted and transanal anterior resection are lacking. This cohort of 11 dedicated rectal cancer centers (https://doi.org/10.1245/s10434-021-10805-5) was unable to show a difference in 3-year overall survival, disease-free survival, or local recurrence among the three techniques.

(C) The Author(s) 2022

E. C. J. Consten, MD, PhD

e-mail: ecj.consten@meandermc.nl 
Laparoscopic Versus Robot-Assisted Versus Transanal Low Anterior Resection -

3-year Oncological Results of a Population-Based Cohort in Experienced Centers

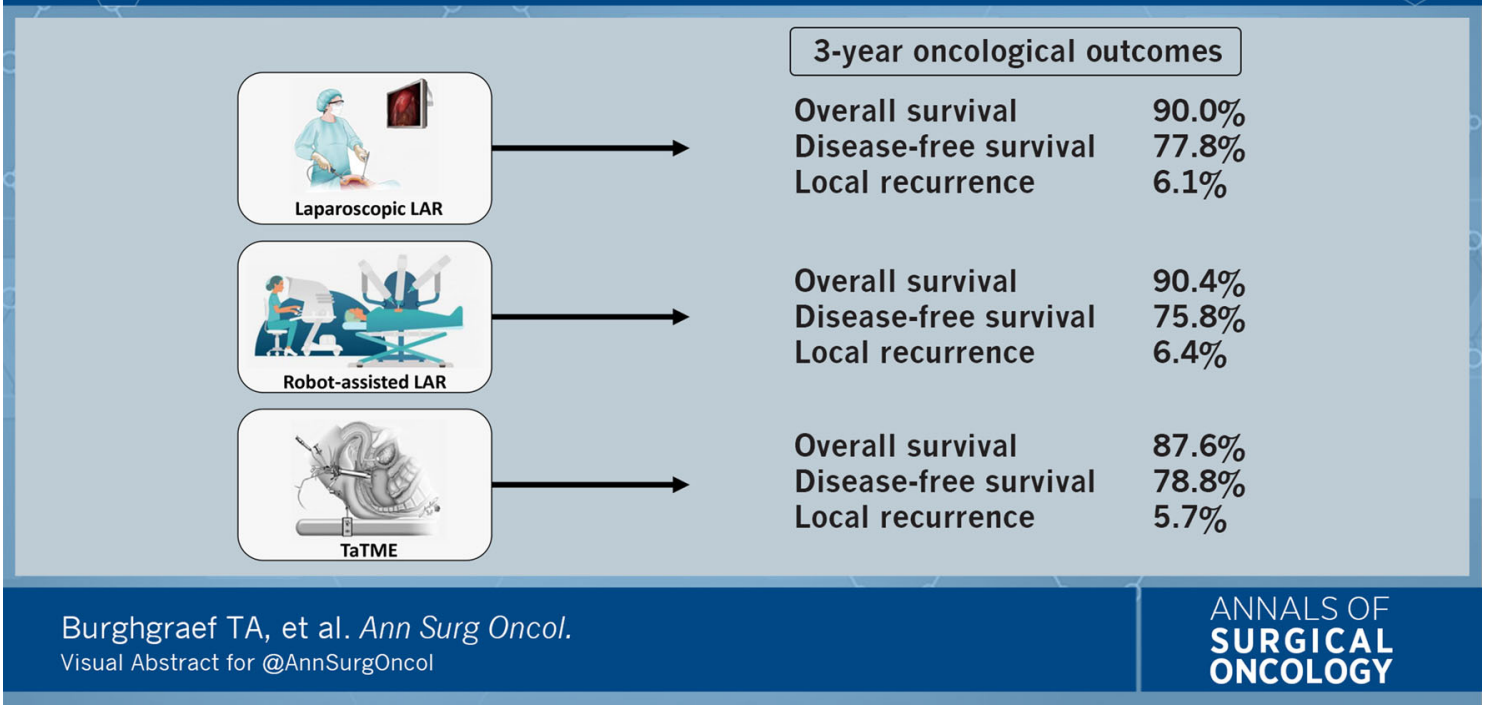

DISCLOSURE Crolla, Verheijen, and Consten receive fees from Intuitive Surgical. No funding was received for this study. The remaining authors have no conflicts of interest.

OPEN ACCESS This article is licensed under a Creative Commons Attribution 4.0 International License, which permits use, sharing, adaptation, distribution and reproduction in any medium or format, as long as you give appropriate credit to the original author(s) and the source, provide a link to the Creative Commons licence, and indicate if changes were made. The images or other third party material in this article are included in the article's Creative Commons licence, unless indicated otherwise in a credit line to the material. If material is not included in the article's Creative Commons licence and your intended use is not permitted by statutory regulation or exceeds the permitted use, you will need to obtain permission directly from the copyright holder. To view a copy of this licence, visit http://creativecommons. org/licenses/by/4.0/.

Publisher's Note Springer Nature remains neutral with regard to jurisdictional claims in published maps and institutional affiliations. 